\title{
Naturally occurring quaternary benzo[c]phenanthridine alkaloids selectively stabilize G-quadruplexes
}

Petra Jarosova ${ }^{a}$, Petr Paroulek ${ }^{a}$, Michal Rajecky ${ }^{a}$, Veronika Rajecka ${ }^{a}$, Eva Taborska ${ }^{b}$, Ramon Eritja ${ }^{c}$, Anna Aviñó ${ }^{c}$, Stefania Mazzini ${ }^{\mathrm{d}}$, Raimundo Gargallo ${ }^{\mathrm{e}}$, Petr Taborsky*a

${ }^{a}$ Faculty of Science, Masaryk University, Kamenice 5, Brno 62500, Czech Republic

${ }^{b}$ Faculty of Medicine, Masaryk University, Kamenice 5, Brno 62500, Czech Republic

c Institute for Advanced Chemistry of Catalonia (IQAC-CSIC), CIBER-BBN, Jordi Girona 18-26, E-08034 Barcelona, Spain.

${ }^{d}$ Department of Food, Environmental and Nutritional Sciences (DEFENS), Section of Chemical and Biomolecular Sciences, University of Milan, Via Celoria 2, Milan 20133, Italy;

e Department of Chemical Engineering and Analytical Chemistry, University of Barcelona, Martí i Franquès 1-11, 08028 Barcelona, Spain

\begin{abstract}
In this work, the interaction of six natural benzo[c]phenanthridine alkaloids (macarpine, sanguilutine, sanguirubine, chelerythrine, sanguinarine and chelirubine) with parallel and antiparallel G-quadruplex DNA structures was studied. HT22 corresponding to the end of human telomere and the modified promoter oncogenes c-kit21 and Pu22 sequences have been used. Spectroscopically-monitored melting experiments and fluorescence titrations, competitive dialysis and nuclear magnetic resonance spectroscopy were used with this purpose. The results showed that these alkaloids stabilized G-quadruplex structures in terms of increments of $\mathrm{T}_{\mathrm{m}}$ values (from 15 to $25^{\circ} \mathrm{C}$ ) with high selectivity over duplexes and unfolded DNA. The mode of binding was mainly by stacking on the terminal Gtetrads with stoichiometries 1:2 (DNA:ligand). The presence of non-specific electrostatics interaction was also observed. Overall, the results pointed to a strong stabilization of G-quadruplex structures by these alkaloids.
\end{abstract}

Keywords: benzo[c]phenanthridine alkaloids, G-quadruplex, NMR, competitive dialysis, CD, melting temperatures. 


\section{Introduction}

Quaternary benzo[c]phenanthridine alkaloids (QBAs) belong to the group of isoquinoline alkaloids. QBAs are present in plants from families Fumariaceae, Papaveraceae, Ranunculaceae and Rutaceae. In addition to relatively common alkaloids such as sanguinarine and chelerythrine, other less common alkaloids such as sanguilutine, macarpine, sanguirubine or chelirubine have been extracted (Figure 1 and S1) ${ }^{1}$. Some of these have proven antiproliferative effects on skin melanoma cells. ${ }^{2}$ Chelerythrine and sanguinarine, as they are commercially available, have been investigated worldwide and their ability to inhibit some important enzymes in cancer cell division has been demonstrated many times. ${ }^{3-5}$ Macarpine, which is found in plants in very small amounts, was first artificially prepared by T. Ishikawa ${ }^{6}$. This alkaloid and its derivatives also show strong cytotoxic effects in cancer cells. ${ }^{7}$ In the case of chelirubine and sanguirubine, antimicrobial, anti-parasitic and anticancer effects have been demonstrated. ${ }^{8,9}$ Besides these various biological effects on cells ${ }^{2}{ }^{10}, \mathrm{QBA}^{\prime} \mathrm{s}$ in their iminium form were reported to interact with double stranded DNA (dsDNA) with a relatively weak mode ${ }^{1,11}$ and comparable to that of ethidium bromide ${ }^{12}$. This interaction leads to changes in their fluorescent properties. Because of these changes, QBAs could also be used as fluorescent DNA probes.

Other DNA secondary structures have gained interest in recent years. One of these structures is the G-quadruplex (GQ) which is present in several protooncogenic-DNA promoters and thus participates in biological processes such as replication, transcription and translation ${ }^{13,14}$. The building blocks of these structures are the G-tetrads: almost planar arrangements of four guanine bases bonded by eight Hoogsteen hydrogen bonds (Figure 1). The G-quadruplex structure can be formed by the intermolecular association of four DNA molecules, by the dimerization of two molecules that contain two G-tracts, or by the intramolecular folding of a single molecule that contains four G-tracts. The topology of G-quadruplexes may be parallel, antiparallel or hybrid, depending on the spatial orientation of the four G-tracts.

A great interest is observed in the potential of G-quadruplex as anticancer target ${ }^{15}$ being the enzymatic activity inhibited by small ligands which stabilize the G-quadruplex. ${ }^{16}$ In this work, the ability of natural alkaloids to stabilize GQ structures has been studied considering several relevant DNA sequences that have been shown previously to form antiparallel and parallel GQ structures (Table 1).

The HT22 sequence, $5^{\prime}-A\left(G_{3} T_{2} A\right)_{3} G_{3}-3^{\prime}$, corresponds to the end of the human telomere and may adopt different Gquadruplex structures depending on the environmental conditions. To date, at least five distinct intramolecular Gquadruplex folding topologies have been reported for natural human telomeric repeats ${ }^{17,}{ }^{18}$, four of which were observed in the presence of $\mathrm{K}^{+}$ions ${ }^{19}$. The crystal structure of this sequence in the presence of $\mathrm{K}^{+}$formed a parallel intramolecular G-quadruplex ${ }^{20}$. Subsequent studies suggested that the intramolecular G-quadruplex structure observed in the $\mathrm{K}^{+}$-containing crystal appears unlikely to be the major form in $\mathrm{K}^{+}$-containing solution. Later, studies have shown that the telomeric sequence can form a mixed ( 3 parallel +1 antiparallel) structure in $\mathrm{K}^{+}$solution ${ }^{21}$. More recently, another form was observed in $\mathrm{K}^{+}$solution, consisting of a two-G-tetrad basket-type core with extensive base stacking interactions in the loops ${ }^{17}$. Finally, an antiparallel $(2+2)$ structure has been observed in $\mathrm{Na}^{+}$solution $^{22}$. Several GQ-forming sequences have been identified within the promoter segment of the human $c-k i t$ oncogene upstream of its transcription initiation site. The 21-mer sequence (5'- $\mathrm{CG}_{3} \mathrm{CG}_{3} \mathrm{CGCGAG}_{3} \mathrm{AG}_{4}-3^{\prime}$, ckit21) forms 
polymorphic G-quadruplex structures. ${ }^{23-25}$ but the mutated sequences (c-kit21T21, Table 1), 5'$\mathrm{CG}_{3} \mathrm{CG}_{3} \mathrm{CGCGAG}_{3} \mathrm{AG}_{3} \mathrm{~T}-3^{\prime}$, and c-kit21T12T21, with one $\mathrm{G}$ to $\mathrm{T}$ mutation at level of 21 and with two $\mathrm{G}$ to $\mathrm{T}$ mutations at level of 12 and 21 residues, respectively, display more simple conformations. The G21T mutation restrains the length of the third loop to a single nucleotide and the fourth G-tract to three guanines. This modification has a significant effect on the biophysical properties, leading to the stabilization of the parallel-stranded topology. ${ }^{26,27}$ The first sequence was used in the present work for $C D$ and fluorescence experiments, the second one for nuclear magnetic resonance (NMR) spectroscopy.

Another important oncogene is c-myc, the overexpression of which is the cause of a wide range of genetic tumors. Pu22 is a 22-mer sequence mainly responsible for the c-myc transcriptional activity ${ }^{16}$. Pu22-14T23T is the same sequence with two $\mathrm{G}$ to $\mathrm{T}$ mutations at position 14 and 23. It adopts the single predominant intramolecular parallel GQ conformation under $\mathrm{K}^{+}$physiological concentration, and thus shows better resolved NMR spectra. Recently, it has been reported that Pu22-14T23T gives the same interactions with ligands as wild type Pu22. ${ }^{28,29}$

In this work, the interaction of six natural benzo[c]phenanthridine alkaloids (macarpine, sanguilutine, sanguirubine, chelerythrine, sanguinarine and chelirubine) with GQ DNA structures formed by HT22, c-kit21T21, c-kit21T12T21 and Pu22T14T23 sequences was studied. Circular dichroism, spectroscopically-monitored melting experiments and fluorescence titrations, competitive dialysis and nuclear magnetic resonance spectroscopy were used with this purpose.

\section{Materials and Methods}

\section{Chemicals}

Alkaloids were extracted from plant material in Department of Biochemistry, Faculty of Science, Masaryk University (Brno, Czech Rep.). Some of the oligonucleotides used in this work (Table 1) were purchased as dry samples from Thermo Fisher Scientific (USA) at HPLC grade. In other cases, DNA synthesis was performed on an Applied Biosystems DNA/RNA 3400 synthesizer by solid-phase 2-cyanoethylphosphoroamidite chemistry. DNAs were desalted in a Sephadex (NAP-10) G25 column and passed through a DOWEX(Na+) resin to exchange ammonium to sodium cations. In all cases, DNAs were diluted in re-distilled water with Trizma ${ }^{\circledR}$ base (10 mM) and EDTA (0.1 mM) buffer $(\mathrm{pH}=8)$ to stabilize them during storage. Other chemicals such Trizma ${ }^{\circledR}$ base $\left(\mathrm{C}_{4} \mathrm{H}_{11} \mathrm{NO}_{3}\right.$, p.a.) and EDTA (p.a.) were obtained from Sigma-Aldrich (USA). Basic chemicals such as $\mathrm{KH}_{2} \mathrm{PO}_{4}, \mathrm{KCl}, \mathrm{NaOH}$ and $\mathrm{KOH}$ (all p.a. grade) were purchased from Lach-Ner (Czech Rep.).

\section{Instruments}

Absorbance spectra were recorded on an Agilent 8453 diode array spectrophotometer (Agilent Technologies; Waldbronn, Germany). Temperature was controlled by means of an Agilent 89090A Peltier device (Agilent Technologies). CD spectra were recorded on a Jasco J-810 spectropolarimeter equipped with a JULABO F-25-HD temperature control unit (Seelbach, Alemania). Fluorescence spectra were measured with an Aminco-Bowman Series 2 spectrofluorimeter (Thermo-Spectronic, USA), equipped with xenon lamp. Temperature was controlled by means of a water bath. Excitation wavelength was depending on QBA used for titration, ranging from 330 to $350 \mathrm{~nm}$. Emission wavelength for complex QBA:DNA was set to $600 \mathrm{~nm}$. In all spectroscopic studies, Hellma quartz cells (10 
$\mathrm{mm}$ path length, and 350, 1500 or $3000 \mu$ volume) were used. The NMR spectra were recorded on a Bruker AV600 spectrometer operating at a frequency of $600.10 \mathrm{MHz}$, equipped with a $5 \mathrm{~mm}$ TXI inverse probe and $z$-axis gradients. The ${ }^{1} \mathrm{H}$ spectra were referenced to external DSS (2,2-dimethyl-2-silapentane-5-sulfonate sodium salt) set at $0.00 \mathrm{ppm}$.

\section{Melting experiments}

In a typical melting experiment, DNA (final concentration $2 \mu \mathrm{M}$ ) was mixed with QBA $(4 \mu \mathrm{M})$ together with phosphate buffer $(10 \mathrm{mM})$ and $\mathrm{KCl}(5 \mathrm{mM})$. The concentration of $\mathrm{KCl}$ was set to $5 \mathrm{mM}$ instead of the most usual 100 or $150 \mathrm{mM}$ concentration in order to reduce the high thermal stability of GQ structures. In this way, the potential stabilization of the GQ by the presence of QBA in terms of $\Delta T_{m}$ could be determined accurately. The sample was heated $\left(96^{\circ} \mathrm{C}\right)$ and then allowed to cool slowly. After several hours, the sample was placed to the instrument (Agilent 8453 UV-Vis or Jasco J815 CD spectrometers). Stirred sample was heated to $96^{\circ} \mathrm{C}$ and cooled down during measurement at a rate of $0.5^{\circ} \mathrm{C} \cdot \mathrm{min}^{-1}$. Sample was measured also during heating process starting from $20^{\circ} \mathrm{C}$ to $96^{\circ} \mathrm{C}$ in the same rate. The absence of hysteresis was checked for some of the QBA:DNA mixtures. Melting temperatures $\left(T_{m}\right)$ were determined as described elsewhere ${ }^{30}$ using home-made routines written in Matlab ${ }^{\circledR}$ code.

\section{Fluorescence experiments}

Fluorescence measurements were performed to determine binding stochiometries and overall association constants according to equation 1 :

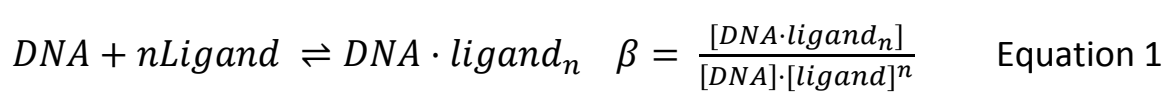

The constants were determined from fluorescence-monitored titrations of QBAs by GQ at $25^{\circ} \mathrm{C}$. In all experiments, the concentration of QBA was kept constant ( $3 \mu \mathrm{M})$ whereas the concentration of the considered GQ was increased. Binding data analysis was done with the OPIUM program. ${ }^{31}$

Alternatively, the Job method was used to determine the binding stoichiometry of the QBA:GQ interaction complex. In this method, the total molar concentration of the two molecules was kept constant, whereas the molar fraction was varied. The total concentration of $\mathrm{QBA}$ and $\mathrm{GQ}$ was $3 \mu \mathrm{M}$. The stoichiometry of the QBA:DNA interaction complex was estimated from the intersection of two lines fitting those points measured at lowest and highest molar fractions.

\section{Competitive dialysis studies}

A $100 \mu \mathrm{l}$ of a $50 \mu \mathrm{M}$ DNA of the different DNA sequences were dissolved in potassium phosphate buffer (185 mM $\mathrm{NaCl}, 185 \mathrm{mM} \mathrm{KCl}, 2 \mathrm{mM} \mathrm{NaH}_{2} \mathrm{PO}_{4}, 1 \mathrm{mM} \mathrm{Na} 2 \mathrm{EDTA}, 6 \mathrm{mM} \mathrm{Na}_{2} \mathrm{HPO}_{4}$ at pH 7 and introduced into a separated dialysis unit (Slide-A-Lyzer ${ }^{\mathrm{TM}}$ MINI device, 3500MWCO, Thermo Fisher) and a blank sample containing only buffer. All dialysis units were allowed to equilibrate during $24 \mathrm{~h}$ at room temperature in a beaker containing the $1 \mu \mathrm{M}$ solution of the appropriate QBA. At the end of the dialysis experiment, the amount of QBA bound to the DNA was quantified by measuring the fluorescence spectra.

\section{Nuclear Magnetic Resonance}

The NMR samples of Pu22-T14T23 and c-kit21T12T21 (Table 1) were prepared at concentration $0.34 \mathrm{mM}$ and 0.42 mM. Pu22-T14T23 was dissolved in $25 \mathrm{mM} \mathrm{KH}_{2} \mathrm{PO}_{4}, 70 \mathrm{mM} \mathrm{KCl}, \mathrm{pH} 6.9$ and ckit21T12T21 was dissolved in $5 \mathrm{mM}$ 
$\mathrm{KH}_{2} \mathrm{PO}_{4}, 20 \mathrm{mM} \mathrm{KCl}, \mathrm{pH}$ 6.9. In these salts condition ckit21T12T21 is present as a monomeric form (Form I). ${ }^{25}$ The DNA samples were heated to $85^{\circ} \mathrm{C}$ for $1 \mathrm{~min}$ and then cooled at room temperature overnight. Stock solution of QBAs were prepared in DMSO- $d 6$ because the sanguilutine was poorly soluble in water.

${ }^{1} \mathrm{H}$ NMR titrations were performed at $25^{\circ} \mathrm{C}$ by adding increasing amounts of the QBA to the DNA at different ratio $\mathrm{R}=[\mathrm{QBA}] /[\mathrm{DNA}]$ and by adding the DNA to a QBA solution in the same experimental conditions.

The NRM signals of the protons in the complexes were assigned by using NOESY and TOCSY experiments. Phase sensitive NOESY spectra were acquired at $25^{\circ} \mathrm{C}$ and $35^{\circ} \mathrm{C}$. The best results were obtained at $25^{\circ} \mathrm{C}$, in TPPI mode, with 2048 x 1024 complex FIDs. Mixing times ranged from 100 ms to 300 ms. TOCSY spectra were acquired with the use of a MLEV-17 spin-lock pulse (60 ms total duration). All spectra were transformed and weighted with a $90^{\circ}$ shifted sine-bell squared function to $4 \mathrm{~K} \times 4 \mathrm{~K}$ real data points. Proton resonance assignments of GG21-T12T21 and Pu22-T14T23 free and complexed were performed on the basis of previous assignments. ${ }^{25,32,33}$ The chemical shift values of the complex of chelerythrine with ckit21T12T21 are reported in Table 2. The chemical shift values of the complexes of Pu22-T14T23 with sanguilutine and chelerythrine are reported in Table S1 and Table S2 respectively. The assignment of the resonances of chelerythrine in the complexes are reported in Tables S3. Some aromatic protons of chelerythrine and sanguilutine lie in a crowded region of the oligonucleotide signals and thus could not be assigned. Pseudo two-dimensional DOSY experiments were acquired using the pulse-program "stebpgp1s", diffusion delay: $0.24-0.36 \mathrm{~s}$; gradient pulse: $1.5 \mathrm{~ms}$; number of increments: 64 . Raw data were processed using the standard DOSY software present in the Bruker library (TOPSPIN v. 1.3).

\section{Results and discussion}

\section{Effect of QBAs on G-quadruplex structure by CD and fluorescence experiments}

First, the overall GQ structures formed by the HT22 and ckit21T21 sequences at the experimental conditions were identified by means of CD spectroscopy (Figure S2). The shape and position of the bands in the CD spectra reflected the overall antiparallel or parallel nature of the GQ structure. Hence, a positive band around $285 \mathrm{~nm}$ indicated the predominance of the antiparallel structure in the case of HT22 sequence, and a negative band around $240 \mathrm{~nm}$ were indications of a parallel structure in the case of the ckit21T21 sequence. In general, the addition of QBA to both HT and ckit21T21 GQ structures did not affect dramatically to the shape and intensity of the CD spectra of DNA recorded in the UV region (Figure S2). This fact was related to the maintenance of the overall GQ structure upon interaction with the ligand. On the other hand, CD measurements in the visible region (Figure S3) did not show the appearance of any significant signal related to induced CD (ICD) in the ligand. It is known that strong ICD signals are usually related to intercalation ${ }^{34}$. Therefore, the absence of ICD points out to another binding mode, such as endstacking or electrostatics. The absence of intercalation, on the other hand, would agree with the fact that the overall $\mathrm{GQ}$ structure is maintained because this mode of interaction probably would alter the DNA structure.

Thermal stabilization

Melting experiments were carried out to observe any positive contribution of QBAs to the thermal stability of GQ structures. It is known that a shift in the unfolding process of $G Q$ in presence of a ligand towards higher temperature values reflects the tendency of the ligand to interact more strongly with the GQ folded species than with the 
unfolded strand ${ }^{35}$. Table 3 summarizes the determined melting temperature $\left(T_{m}\right)$ values in the absence and presence of QBAs.

The melting experiments with antiparallel structure HT22 were monitored either with UV-Vis or CD spectroscopies. The determined $T_{m}$ values in both cases were very similar (within $\pm 0.5^{\circ} \mathrm{C}$ ). Melting temperature of $\mathrm{HT} 22$ was found to be $51.0^{\circ} \mathrm{C}$ (Figure 2). Practically no changes between melting temperatures calculated from data obtained during cooling or heating the studied systems were observed (Figure S4), which ruled out the presence of hysteresis. In general, all other QBAs produced a clear stabilization of this $G Q$ structure. The highest $T_{m}$ value in case of HT22 was observed for sanguinarine $\left(\Delta \mathrm{T}_{\mathrm{m}}=18.1^{\circ} \mathrm{C}\right)$, which reflects a greater tendency of this ligand to interact with the folded $G Q$ structure than with the unfolded strand. On the other hand, macarpine $\left(\Delta T_{m}=-0.9{ }^{\circ} \mathrm{C}\right)$ showed a similar tendency to interact with both species (GQ folded and unfolded strand).

Melting experiments on parallel structure ckit21T21 were exclusively made by CD spectrometry because of the low absorbance changes observed at $295 \mathrm{~nm}$ during measurements (see an example in Figure S5). The $\mathrm{T}_{\mathrm{m}}$ value of ckit21T21 was found to be $50.0^{\circ} \mathrm{C}$. In this case, the most conspicuous shifts in case of ckit21T21 were observed for chelirubine $\left(\Delta \mathrm{T}_{\mathrm{m}}=24.5^{\circ} \mathrm{C}\right)$ and sanguilutine $\left(\Delta \mathrm{T}_{\mathrm{m}}=22.4^{\circ} \mathrm{C}\right)$. Again, macarpine showed the lowest GQ-stabilization properties, as $\mathrm{T}_{\mathrm{m}}$ only increased $6.3^{\circ} \mathrm{C}$. To our knowledge, the stabilizing propierties showed by chelirubine is one of the highest observed differences in melting values for parallel GQ structures. ${ }^{33,} 36,37$ As example, the model ligand TMPyP4 stabilizes telomeric DNA less than selected alkaloids about $\left(\Delta \mathrm{T}_{\mathrm{m}}=1-13^{\circ} \mathrm{C}\right)$ at the same concentration ratio. ${ }^{37-39}$

In general, the studied alkaloids show $\Delta T_{m}$ values higher in the case of parallel GQ (ckit21T21) than in the case of antiparallel (HT22) structures. This fact may be related to the different loop geometry in both structures, as the GQ core formed by three G-tetrads is similar. It seems that these alkaloids interact much better with a structure showing double-chain reversal loops, like ckit21T21.

For a given $\mathrm{GQ}$ structure, the determined $\Delta \mathrm{T}_{\mathrm{m}}$ values may be qualitatively correlated with the presence and nature of substituents in the benzo[c]phenanthridine skeleton of the considered QBAs (Figures 1 and S1). For HT22, the ligands that shift the most the $T_{m}$ value of the GQ structure were those showing an $-\mathrm{H}$ atom at $\mathrm{R} 5$ position, and $-\mathrm{O}-\mathrm{CH}_{2}-\mathrm{O}$ group between R1 and R2. Sanguinarine and and chelirubine (the most stabilizing ligands) have also lower value of $\mathrm{pK}_{\mathrm{R}+}$ in comparison to other alkaloids (8.05 and 7.7 respectively) ${ }^{40}$. The substitution on R4, R6, or R3 does not have any significant influence on $\Delta T_{m}$. For ckit21T21, the ligands showing significant $\Delta T_{m}$ values are those having an $-H$ atom at $\mathrm{R} 6$, and no- $-\mathrm{OCH}_{2}-\mathrm{O}-$ group between $\mathrm{R} 3$ and $\mathrm{R} 4$.

The weaker stabilization induced by macarpine in both GQ structures could be due to steric effects related with the additional $-\mathrm{O}-\mathrm{CH}_{3}$ group at position R6 (Figures 1 and S1). All the other alkaloids, which do not include R6 group, showed GQ-stabilizing properties.

\section{Selectivity}

At this point, it is necessary to mention that melting experiments with dsDNAs and QBAs did not show any significant increase of melting temperature $\left(\Delta \mathrm{T}_{\mathrm{m}}<2^{\circ} \mathrm{C}\right.$ ) (Figure 2b). Therefore, QBAs appeared as a potential selective group of ligands to bind $G Q$ structures. To gain more information about the selectivity of QBAs for DNA structures or sequences, competitive dialysis experiments were performed (Figure 3 and Table S4) ${ }^{41}$. In these, a set of dialysis 
units containing different DNA sequences, some of them prone to form folded structures, is placed inside a solution of the considered ligand. After an equilibration period, part of the ligand enters to the dialysis units depending on its selectivity towards each sequence or structure, as well on the binding stoichiometry. Quantification is done by measuring emission fluorescence at $600 \mathrm{~nm}$. In this work, a set of different DNA sequences (Table 1) representing several nucleic acid structures was used. ${ }^{16,25,28,42}$ T20 was used as model for an unfolded single-stranded DNA sequence. As models of dsDNA, the self-complementary sequences Dickerson-Drew dodecamer and a 26-mer hairpin (ds26) were used.

It was observed that the measured fluorescence in tubes containing DNA sequences was much higher than that measured for the blank. Therefore, it was clear that all ligands showed a strong tendency to interact with the stable DNA structures formed by the considered sequences at $20^{\circ} \mathrm{C}$, approximately. It is difficult to extract quantitative information from this experiment as ligands show slightly different values of quantum yields. Moreover, the binding stoichiometry may be different among DNA sequences, affecting to the measured fluorescence. However, some information may be extracted. First, all alkaloids show low tendency to interact with T20 sequence, which forms a rather unfolded species at these conditions. Second, even though double stranded structures formed by ds 26 and Dickerson show more binding sites than compact $G Q$ structures, the fluorescence intensity is higher for $G Q$ structures, such as HT22, ckit21T21 or bcl-2. This fact was clear in the cases of sanguinarine (SG) or chelerythrine (CHE). Finally, for some alkaloids, such as chelerytrhine or sanguilutine (SL), which show a binding stoichiometry 1:3 for both HT22 and ckit21T21 GQ structures (see below), the fluorescence intensity is higher for the parallel structure than for the antiparallel one.

\section{Determination of DNA:ligand stoichiometry}

The interaction of GQ with the QBAs causes an increase of their intrinsic fluorescence that can be used to determine stoichiometries and to calculate binding constants (Figure 4) by means of mole-ratio experiments. In these, the concentration of QBA was kept constant $(3 \mu \mathrm{M})$ whereas the concentration of the considered $G Q$ was increased along the experiment. At the temperature of the experiment, $25^{\circ} \mathrm{C}, \mathrm{GQ}$ structures are completely folded as the corresponding $T_{m}$ values are higher than $50^{\circ} \mathrm{C}$. On the other hand, the emission was measured in a region (500 - 600 $\mathrm{nm}$ ) where the potential inner effect filter due to absorption of the titrant (around 260-300 nm) cannot be produced.

Figure 4a shows the titration of MA with HT22. The titration curve showed the typical sharp initial slope of intensity with increase of $G Q$ concentration indicating a strong interaction. At higher concentration of $G Q$, instead of the expected constant fluorescence intensity, the signal was continuously increasing. The continuous increase of fluorescence intensity could be caused by the intrinsic fluorescence of DNA bases or by non-specific interaction between DNA and alkaloid ${ }^{1}$. To remove this effect from the overall titration curve, the dependence of the fluorescence of macarpine with the unfolded oligonucleotide $(A)_{12}$ concentration was measured (bottom curve). The contribution of this fluorescence signal was removed before the calculation of constants, yielding the curve with flat top shown in Figure 4b. From titration curves binding stoichiometry and stability constants were estimated (Table 3). Best fitting models were found to have (GQ:QBA) stoichiometry 1:3 or 1:4. Additional experiments based on Job's method provided similar values of stoichiometry (selected examples are shown in Figure S6). 
The 1:3 stoichiometry was the best fit for both studied GQ structures with almost all alkaloids. At neutral pH QBAs are mostly in iminium (positively charged) form as their $\mathrm{pK}_{R_{+}}$values lie between 7.7 and $9^{43}$. As previously reported, QBAs in iminium form interact with dsDNA forming highly luminescent complexes. ${ }^{44}$ Although there is no clear evidence for the mechanism of interaction with dsDNA, it is supposed that planar positively charged alkaloids are intercalated between base pairs of DNA and due to this incorporation, the luminescence is enhanced (except for sanguinarine). A similar enhancement of the luminescence emission was observed also for mixtures of QBAs with $\mathrm{GQ}$. However, the intercalation mechanism does not seem a very plausible possibility, as pointed out by $C D$ measurements, because of insufficient space for the ligands between tetrads of $G Q$ which, moreover, are probably occupied by cations ${ }^{45}, 46$. In this sense, the stoichiometries determined in this work are far from the 1:1 (GQ:QBA) stoichiometry described by Bhadra ${ }^{47}$ for sanguinarine, coralyne, palmatine and berberine with $5^{\prime}-A_{3}\left(T_{2} A G_{3}\right)_{3}-3^{\prime}$. However, it should be taken into account that the experimental conditions were different, and these could not only affect to the GQ structure (which was an hybrid parallel/antiparallel in that work) but also to the presence of additional interactions.

Xiong et al. ${ }^{48}$ described three possible binding modes of heterocyclic alkaloids: stacking on the top or bottom Gquartets, groove binding and loop binding. Although it is not possible to assign exact binding mode of interaction from spectroscopic experiments, it seems that there exist $\sim 3$ binding sites occupied by molecules of QBA with similar energetic leve ${ }^{42,} 49$. Enhancement of fluorescence at $620 \mathrm{~nm}$ (like intercalation) would be explained by stacking $(\pi-\pi$ stacking interaction) of QBA to structure of GQ resulting in low fluorescence quenching by water molecules or other quenchers present in solvent. The stacking interaction is also reported by other authors ${ }^{50,51}$ and it is in agreement with observation provided by Shu et al..$^{42}$ and Bhadra et al. ${ }^{47}$ for sanguinarine.

Interaction of chelerythrine with GG21-T12T21 sequence and of sanguilutine and chelerythrine with Pu22-T14T23 sequence

NMR experiments were used to study the mode of binding of these alkaloids with the G-quadruplex structures.

The addition of chelerythrine to c-kit21T12T21 solution even at low ratio $R=[$ ligand]/[DNA] $=0.5 / 1.0$ produced an upfield shift and a generalized broadening of $\mathrm{H} 1$ imino protons. The signals remain broad till the ratio $\mathrm{R}=3.0$ was reached and a precipitate is formed (Figure 5). The assignment of the protons involved in the tetrads for the complexes and for the free nucleotides was performed by a combined used of a) the inter-residue NOE interactions between $\mathrm{H} 1$ imino protons (Table S5), b) the titration experiments and c) the inter-residue NOE connectivities between the $\mathrm{H} 1$ imino and aromatic $\mathrm{H} 8$ of guanine residues.

A large change in the chemical shifts of the $\mathrm{H} 1$ imino protons $(\Delta \delta \geq 0.80 \mathrm{ppm}$ ) was observed both for the $\mathrm{H} 1$ imino protons belonging to outer G-tetrads and for the internal one ( $\Delta \delta \geq 0.40 \mathrm{ppm}$ ) (Table 2). Several NOE contacts were found: the aromatic proton $\mathrm{H} 6$ of chelerythrine with $\mathrm{H} 1$ imino protons of $\mathrm{G} 18, \mathrm{G} 7$ and $\mathrm{G} 19$, the $\mathrm{NCH}_{3}$ protons with G20, and the 8-ethylene-dioxy with G18, suggesting strong interactions of chelerythrine with the oligonucleotide (Table 4). The generalized line broadening of all the signals and the presence of the NOE interactions either with the external and internal tetrads suggest the presence of multiple species in solution with the ligand positioned in different binding sites in chemical exchange. Also, the protons of the chelerythrine in the complex are broad, indicating a certain mobility inside the binding sites. 
To better clarify the mode of binding of these alkaloids with the parallel G-quadruplex structure and to extend our investigation to the sequence responsible for the $c-m y c$ transcription activity we performed the NMR experiments with the Pu22-T14T23 sequence.

The titration with chelerythrine and sanguilutine induced, even at low $\mathrm{R}=[$ ligand]/[DNA] ratio, a broadening of all the signals of DNA and of the ligand. At $R \geq 1.5$ a new set of imino protons signals appeared at up-field shift, and the signals sharpened at $\mathrm{R}=2.0$ (Figure 6). This suggested the formation of a defined complex with two ligand molecules interacting with the GQ structure. A further addition of ligands to Pu22-T14T23 caused only small changes in the H1 imino protons until the $R=3.0$ was reached.

The analysis of the spectra at $\mathrm{R}=3.0$ was performed starting from the attribution of the three tetrads by inter-residue NOE connectivities between the $\mathrm{H} 1$ imino and the aromatic protons $\mathrm{H} 8$ of guanine residues (following the procedure used for the study of other ligands. ${ }^{28,52}$ The results reported in Table S6 show that the quadruplex structure is conserved. Also, for these complexes a significant shielding was observed for the $\mathrm{H} 1$ imino protons of the internal tetrad $(\Delta \delta=-0.30 /-0.60 \mathrm{ppm}$ ) although lower than the values of the external tetrads $(\Delta \delta \geq-0.60 \mathrm{ppm})$. In particular, it is relevant the $\Delta \delta=-1.36 \mathrm{ppm}$ observed for the G16H1 of the chelerythrine complex (Tables S1 and S2).

Sanguilutine showed NOE contacts of $\mathrm{H} 6$ with G22 H1. Other NOEs were found between some aromatic protons and $\mathrm{H} 1$ imino protons of G9, G18 and G22 belonging to the 3'-end tetrad. The methyl signal confirms the contacts to all these units and to $\mathrm{G} 11 \mathrm{H} 1$ belonging to the $5^{\prime}$-end tetrad. Due to the low solubility of the sanguilutine, the identification of all the aromatic protons of the ligand was difficult. The NMR spectra of chelerythrine complex instead are of better quality and all the proton signals of the ligand were identified. NOEs were found between the $\mathrm{N}$-methyl and the aromatic protons $\mathrm{H} 4$ and $\mathrm{H} 6$ of the ligand with the $\mathrm{H} 1$ imino protons of $\mathrm{G} 7, \mathrm{G} 11$ and $\mathrm{G} 16$ units at 5'-end. The same protons of the ligand also show NOE contacts with units at 3'-end, i.e. G9, G22, G18 and/or G13 (Table 5) (figure 7). These results gave evidence of the location of chelerythrine over both the outer G-quartets.

DOSY experiment, performed on the complex with chelerythrine, showed a diffusion coefficient indicating that the stoichiometry of the complex may be more than two ligands for G-quadruplex and excludes a higher aggregation of the nucleotide. The significant upfield chemical shifts of the imino protons belonging to the internal tetrad are difficult to be explained but they can suggest an interaction also at the level of this tetrad.

\section{Conclusions}

The interaction between human telomeric DNA (HT22) and modified c-kit structure (ckit21T21) and six plant benzo[c]phenanthridine alkaloids were studied by various spectroscopic techniques. Although these alkaloids have similar structure, they exhibit different contribution to stabilization of G-quadruplex structures as demonstrated with melting experiments. The ligands that mostly shift the $T_{m}$ of $H T 22$ are those showing an $\mathrm{H}$ atom at R5 position, and $-\mathrm{O}-\mathrm{CH}_{2}-\mathrm{O}$ - group between R1 and R2. Sanguinarine and chelerythrine were found to be good stabilizers of both anti-parallel and parallel structures as those present in the segment of human telomeric and in the modified 21-mer of c-kit2 sequences. Alkaloid chelirubine was found to be excellent stabilizer of parallel GQ structure ckit21T21. 
The NOESY experiments, performed with c-kit21T12T21 and Pu22T14T23 sequences, show that sanguilutine and chelerythrine have NOEs contacts with units at $3^{\prime}$ and $5^{\prime}$ end, with two molecules being located respectively over the outer tetrads.

The possibility that the ligand molecules may interact also at the level of the internal tetrad is suggested by the strong shelding of the imino protons signals of these units. This appears more probable for the complex with ckit21T21 sequence, where the ligand positioned in different binding sites appears in chemical exchange.

Also, other studied alkaloids, except macarpine, have shown strong stabilizing effect, forming 1:3 or 1:4 complexes with GQ. These compounds seem to be potential selective GQ ligands as they practically do not stabilize the B-DNA duplex structure.

Overall, these results suggest the potential use of these minor, non-commercial QBAs as G-quadruplex stabilizers in vivo, or for the development of analytical methods based on fluorescence spectroscopy.

\section{Acknowledgments}

Funding from Spanish government (CTQ2015-66254-C2-2-P and CTQ2017-84415-R) and recognition from the Autonomous Catalan government (2017SGR114) are acknowledged. This work was also supported by the project KONTAKT II LH12176 from Ministry of Education, Youth and Sports of the Czech Republic. 
Figure and table legends

Table 1. DNA sequences used in this work.

\begin{tabular}{|c|c|c|}
\hline Code & Sequence $\left(5^{\prime} \rightarrow 3^{\prime}\right)$ & Proposed structure \\
\hline HT22 & A $(\text { GGGTTA })_{3 G G G}$ & Antiparallel G-quadruplex \\
\hline ckit21T21 & CGGGCGGGCGCGAGGGAGGGT & Parallel G-quadruplex \\
\hline ckit21T12T21 & CGGGCGGGCGCTAGGGAGGGT & Parallel G-quadruplex \\
\hline Pu22-T14T23 & TGAGGGTGGGTAGGGTGGGTAA & Parallel G-quadruplex \\
\hline T20 & T $20^{2}$ & Unfolded strand \\
\hline ds26 & CAATCGGATCGAATTCGATCCGATTG & Duplex hairpin \\
\hline Dickerson & CGCGAATTCGCG & Duplex \\
\hline bcl-2 & CGGGCGCGGGAGGAAGGGGGCGGG & Hybrid G-quadruplex \\
\hline$(G C)_{6}$ & GCGCGCGCGCGC & Duplex \\
\hline
\end{tabular}


Table 2. ${ }^{1} \mathrm{H}$ chemical shift values for the complex of chelerythrine with c-kit21T12T21. ${ }^{a}$

\begin{tabular}{|c|c|c|c|c|}
\hline & $\mathrm{H} 1 / \mathrm{H} 2 / \mathrm{H}_{5} / \mathrm{CH}_{3}$ & $\Delta \delta^{\mathrm{b}}$ & $\mathrm{H} 6 / \mathrm{H} 8$ & $\Delta \delta^{\mathrm{b}}$ \\
\hline C1 & 6.08 & +0.53 & 7.55 & +0.05 \\
\hline G2 & 11.15 & -0.81 & 8.03 & -0.17 \\
\hline G3 & 10.88 & -0.42 & 7.69 & -0.09 \\
\hline G4 & 10.42 & -0.73 & 7.70 & -0.05 \\
\hline C5 & 6.22 & +0.02 & 7.81 & -0.23 \\
\hline G6 & n.d. & - & n.d. & - \\
\hline G7 & 11.07 & -0.51 & 7.84 & -0.18 \\
\hline G8 & 10.48 & -0.83 & 7.76 & -0.03 \\
\hline C9 & 6.20 & +0.10 & 7.62 & 0.00 \\
\hline G10 & n.d. & - & 8.03 & +0.04 \\
\hline C11 & 6.10 & +0.04 & 7.94 & +0.04 \\
\hline T12 & 1.88 & -0.02 & 7.50 & -0.10 \\
\hline A13 & n.d. & - & 8.28 & +0.18 \\
\hline G14 & 11.10 & -0.84 & n.d. & - \\
\hline G15 & 10.78 & -0.40 & 7.68 & -0.19 \\
\hline G16 & 10.25 & -0.79 & 7.69 & -0.09 \\
\hline A17 & n.d. & - & 8.56 & +0.03 \\
\hline G18 & 10.69 & -1.13 & n.d. & - \\
\hline G19 & 11.02 & -0.50 & 7.77 & -0.32 \\
\hline G20 & 10.45 & -0.80 & 7.73 & +0.03 \\
\hline T21 & n.d. & & n.d. & - \\
\hline
\end{tabular}

${ }^{a}$ Measured at $25^{\circ} \mathrm{C}$ in ppm ( $\delta$ ) from external DSS. Solvent $\mathrm{H}_{2} \mathrm{O}-\mathrm{D}_{2} \mathrm{O}(90: 10 \mathrm{v} / \mathrm{v}), 5 \mathrm{mM}$ phosphate buffer, $20 \mathrm{mM} \mathrm{KCl}, \mathrm{pH} 6.9, \mathrm{R}=$ 3. ${ }^{b} \Delta \delta=\delta_{\text {bound }}-\delta_{\text {free }}$ 
Table 3. GQ stabilization by QBAs in melting and binding experiments. The experimental conditions of melting studies were $2 \mu \mathrm{M} \mathrm{GQ}, 4 \mu \mathrm{M}$ QBA, $10 \mathrm{mM}$ phosphate buffer, $5 \mathrm{mM} \mathrm{KCl}, \mathrm{pH}$ 7.0. In the case of binding studies, the experimental conditions were $3 \mu \mathrm{M}$ QBA, $10 \mathrm{mM}$ phosphate buffer, $5 \mathrm{mM} \mathrm{KCl}, \mathrm{pH} 7.0,25{ }^{\circ} \mathrm{C}$. GQ concentration varied from 0 to $10 \mu \mathrm{M}$. $\mathrm{T}_{\mathrm{m}}$ values were determined from two replicates. In all cases, incertitude values are below 1 ${ }^{\circ} \mathrm{C}$. Figures written in italics are only estimated values because of high experimental error.

\begin{tabular}{|c|c|c|c|c|c|}
\hline GQ & QBA & $\mathrm{T}_{\mathrm{m}}\left[{ }^{\circ} \mathrm{C}\right]$ & $\Delta \mathrm{T}_{\mathrm{m}}\left[{ }^{\circ} \mathrm{C}\right]$ & $\begin{array}{c}\text { Proposed } \\
\text { stoichiometry }\end{array}$ & $\begin{array}{l}\text { Logarithm of overall formation constant } \beta \\
\text { (standard deviation) }\end{array}$ \\
\hline \multirow[t]{7}{*}{ HT22 } & no alkaloid & 51.0 & - & - & - \\
\hline & Macarpine (MA) & 50.1 & -0.9 & $1: 5$ & $31.3(0.1)$ \\
\hline & Chelirubine (CHR) & 64.6 & 13.6 & $1: 4$ & $24.5(0.2)$ \\
\hline & Sanguinarine (SG) & 69.1 & 18.1 & $1: 3$ & $\sim 16$ \\
\hline & Chelerythrine (CHE) & 63.3 & 12.3 & $1: 3$ & $17.1(0.1)$ \\
\hline & Sanguirubine (SR) & 62.2 & 11.2 & $1: 3$ & $19.3(0.1)$ \\
\hline & Sanguilutine (SL) & 57.6 & 6.6 & $1: 3$ & $19.1(0.1)$ \\
\hline \multirow[t]{7}{*}{ ckit21T21 } & no alkaloid & 50.0 & - & - & - \\
\hline & Macarpine (MA) & 56.3 & 6.3 & $1: 3$ & $17.6(0.1)$ \\
\hline & Chelirubine (CHR) & 74.5 & 24.5 & $1: 3$ & $17.3(0.1)$ \\
\hline & Sanguinarine (SG) & 65.5 & 15.5 & $1: 4$ & $\sim 22$ \\
\hline & Chelerythrine (CHE) & 70.7 & 20.7 & $1: 3$ & $\sim 15$ \\
\hline & Sanguirubine (SR) & 70.8 & 20.8 & $1: 4$ & $23.9(0.1)$ \\
\hline & Sanguilutine (SL) & 72.4 & 22.4 & $1: 3$ & $17.9(0.1)$ \\
\hline
\end{tabular}


Table 4. Inter-molecular NOE in the complex of chelerythrine with c-kit21T12T21. Experimental data acquired at $25^{\circ} \mathrm{C}$ in $\mathrm{H}_{2} \mathrm{O}-\mathrm{D}_{2} \mathrm{O}(90: 10 \mathrm{v} / \mathrm{v}), 5 \mathrm{mM}$ phosphate buffer, $20 \mathrm{mM} \mathrm{KCl}, \mathrm{pH} 6.9$.

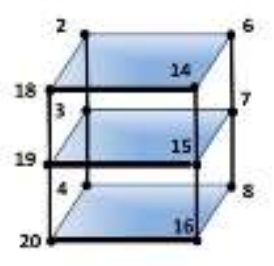

\begin{tabular}{lc}
\hline Ligand & c-kit21TT12T21 \\
\hline $\mathrm{H} 6$ & $\mathrm{G} 7 \mathrm{H} 1$ \\
$\mathrm{H} 6$ & $\mathrm{G} 18 \mathrm{H} 1$ \\
$\mathrm{H} 6$ & $\mathrm{G} 19 \mathrm{H} 1$ \\
$\mathrm{O}-\mathrm{CH}_{2}-\mathrm{O}$ & $\mathrm{G} 18 \mathrm{H} 1$ \\
$\mathrm{NCH}_{3}$ & $\mathrm{G} 2 \mathrm{H} 1$ \\
\hline
\end{tabular}


Table 5. Inter-molecular NOE in the complex of chelerythrine with Pu22-T14T23. Experimental data acquired at $25^{\circ} \mathrm{C}$ in $\mathrm{H}_{2} \mathrm{O}-\mathrm{D}_{2} \mathrm{O}(90: 10 \mathrm{v} / \mathrm{v}), 25 \mathrm{mM}$ phosphate buffer, $70 \mathrm{mM} \mathrm{KCl}, \mathrm{pH} 6.9$.

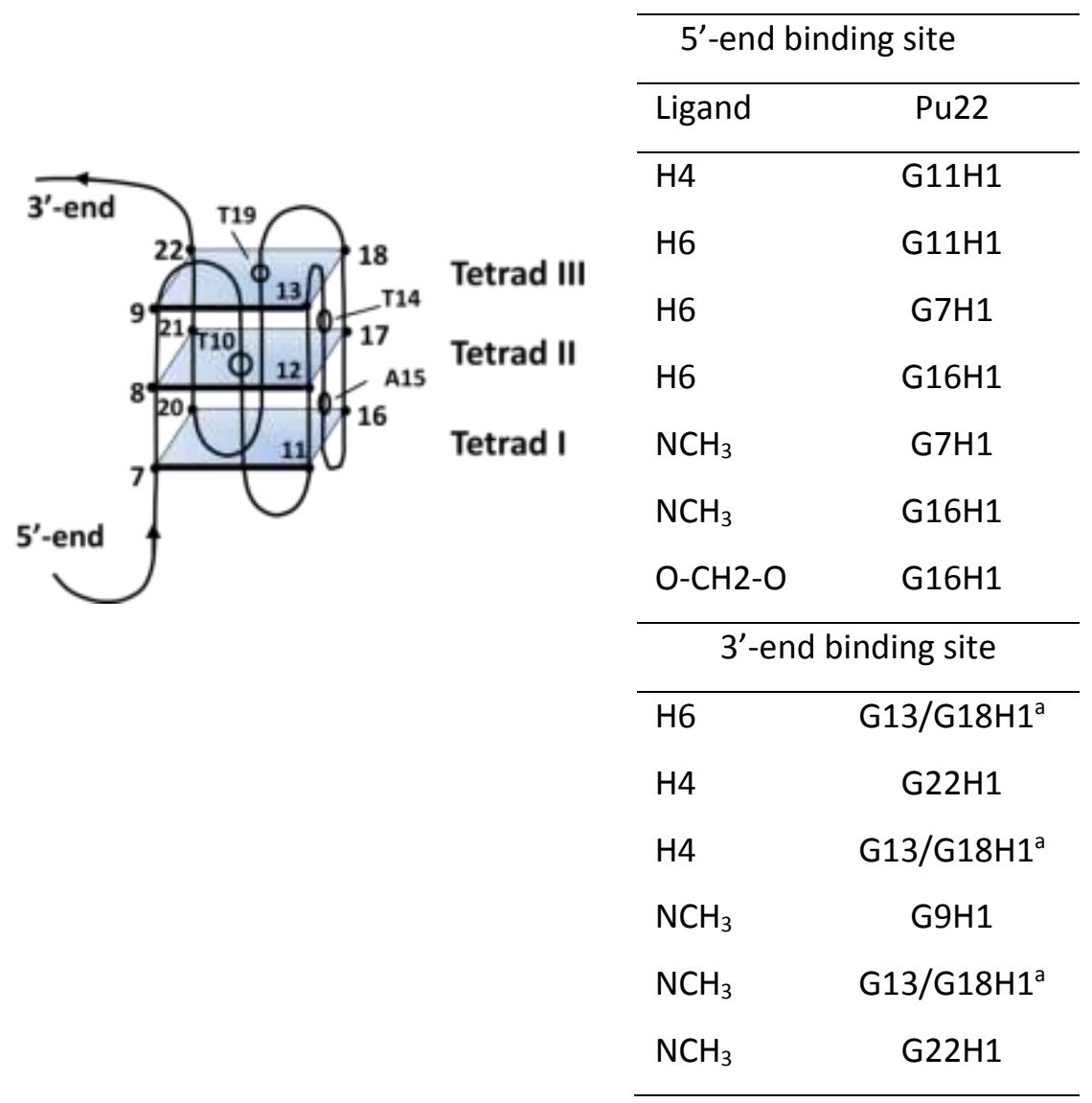

${ }^{a}$ The two signals are overlapped 
Figure 1. General structure of QBAs and G-quadruplex. (a) General formula of QBAs and acid-base equilibria. (b) Nomenclature and substitutions of the QBAs studied in this work. (c) Planar arrangement of four guanine bases in a G-tetrad. (d) Three different topologies of G-quadruplex structures depending on the spatial arrangement of Gtracts.

a

b

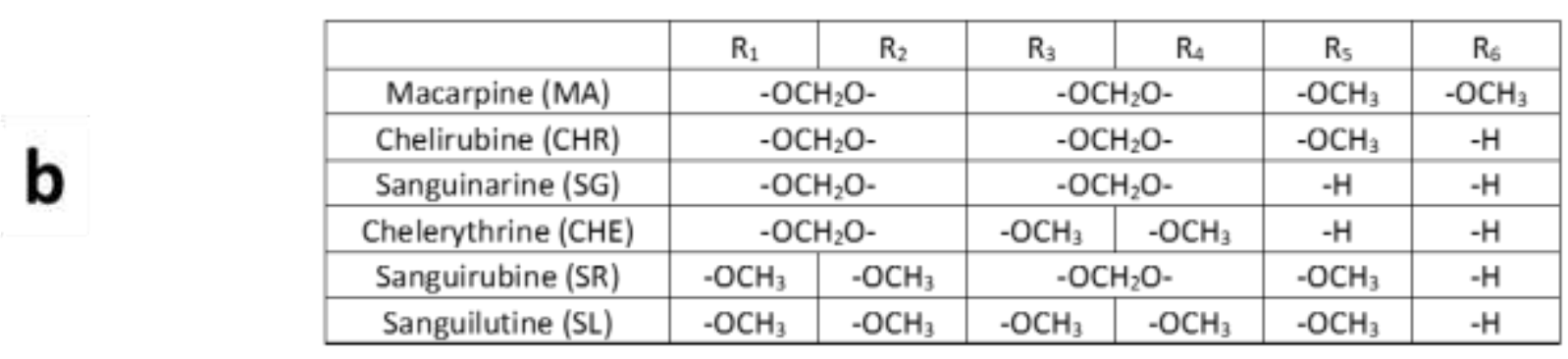
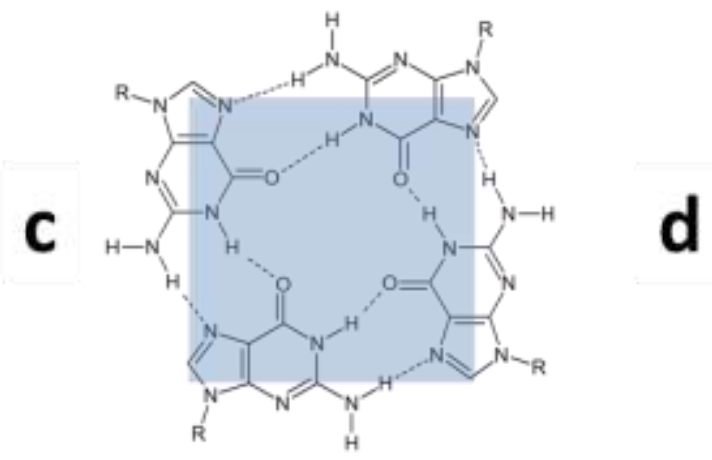

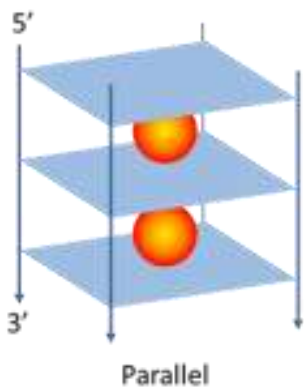

Parallel<smiles></smiles>

iminium $\left(Q^{+}\right)$

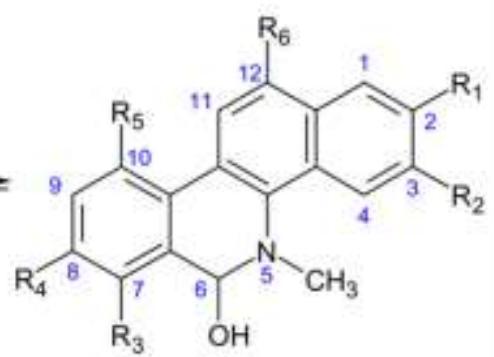

alkanolamine $(\mathrm{QOH})$

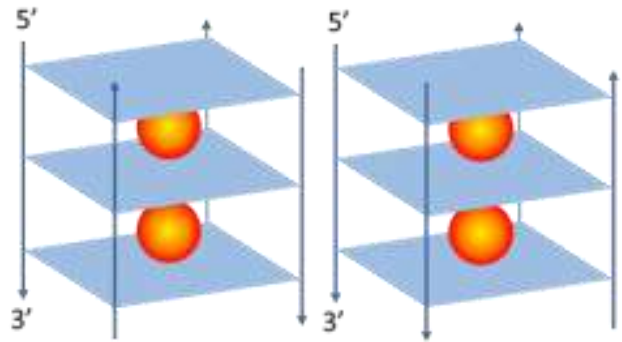

Anti-parallel 
Figure 2. Melting experiments. (a) Normalized melting curves of ckit21T21 (black) with macarpine (blue), chelerythrine (violet), sanguirubine (yellow), sanguinarine (orange), sanguiltuine (green) and chelirubine (red). (b) Normalized melting curves of (GC) 6 dsDNA (black) with macarpine (blue) and chelirubine (red). In all cases, $C_{D N A}=2$ $\mu \mathrm{M}, \mathrm{C}_{\mathrm{QBA}}=4 \mu \mathrm{M}, 10 \mathrm{mM}$ phosphate buffer, $5 \mathrm{mM} \mathrm{KCl}, \mathrm{pH}$ 7.0.

a

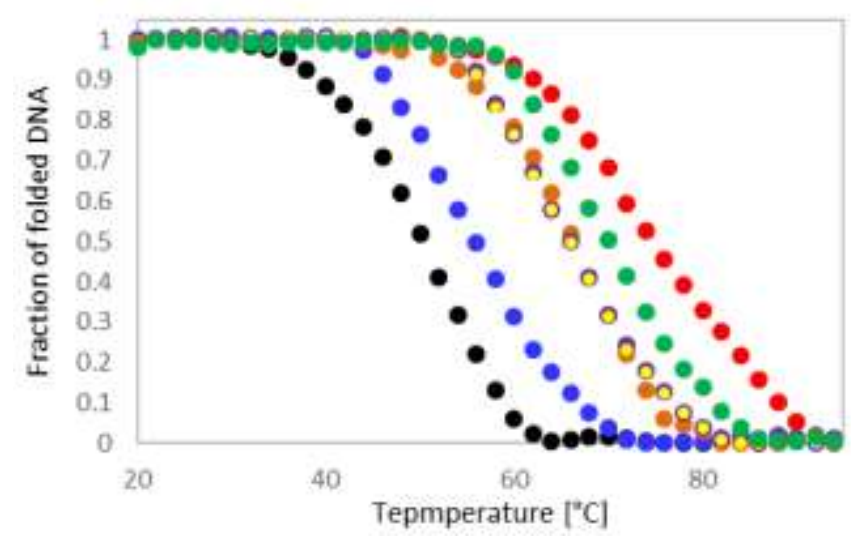

b

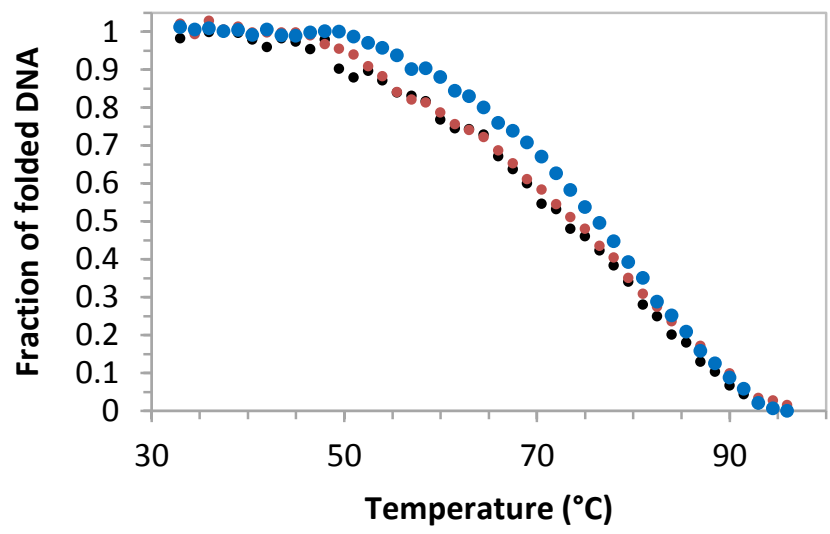

Figure 3. Competitive dialysis assays. Fluorescence intensities of alkaloids with DNA structures. Experimental conditions are explained in the text. The whiskers indicate an incertitude equal to $10 \%$.

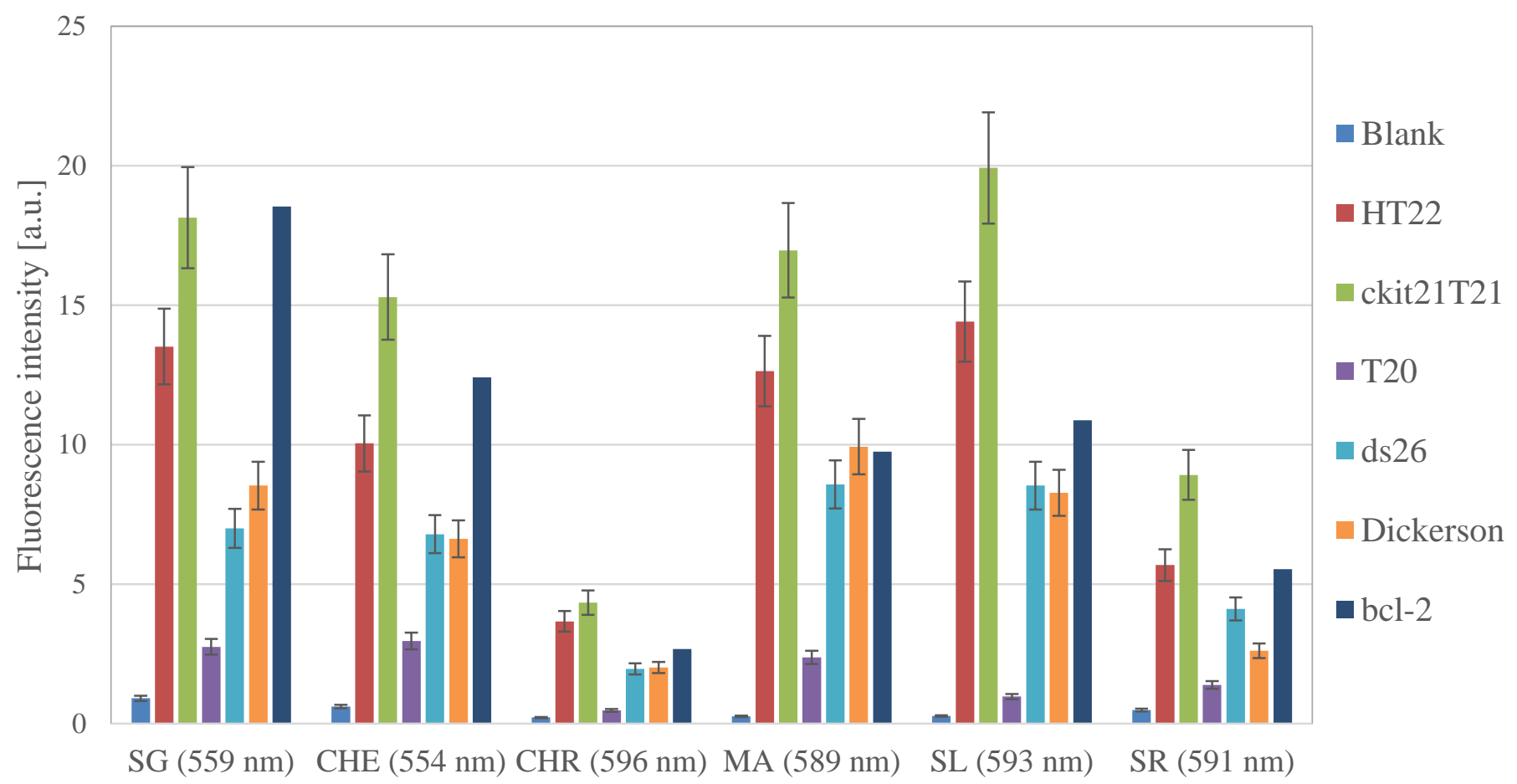


Figure 4. Spectrofluorimetrically-monitored binding studies. (a) Fluorescence spectra recorded along the titration of macarpine: spectrum of macarpine at concentration of $3 \mu \mathrm{M}$ (blue dots) and macarpine with $\mathrm{HT} 22$ at concentration of $20 \mu \mathrm{M}$ concentration (red crosses). Other experimental conditions were $10 \mathrm{mM}$ phosphate buffer, $5 \mathrm{mM} \mathrm{KCl}, 25$ ${ }^{\circ} \mathrm{C}$. (b) original fluorescence signal at $600 \mathrm{~nm}$ for the titration of macarpine at different concentration of HT22 (triangles), fluorescence signal of macarpine with oligonucleotide $(A)_{12}$ representing non-specific interaction (squares) and corrected signal used for fitting (circles).

a

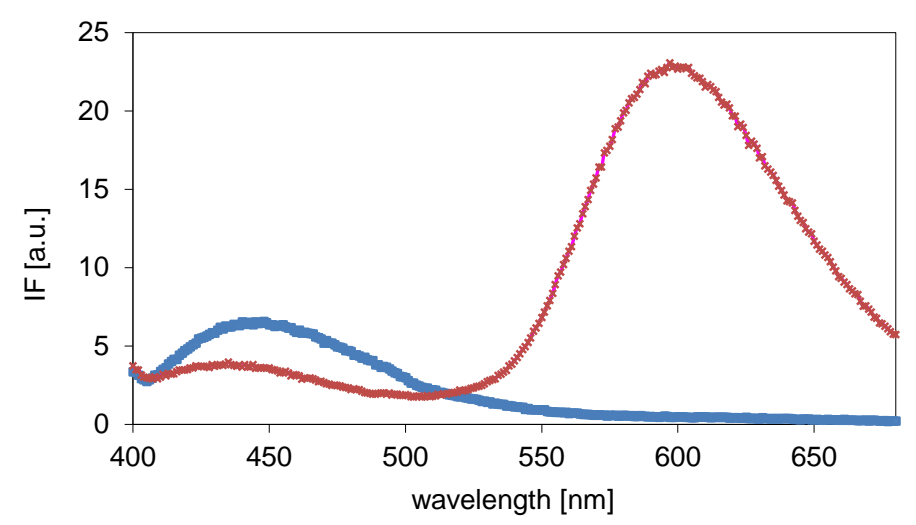

b

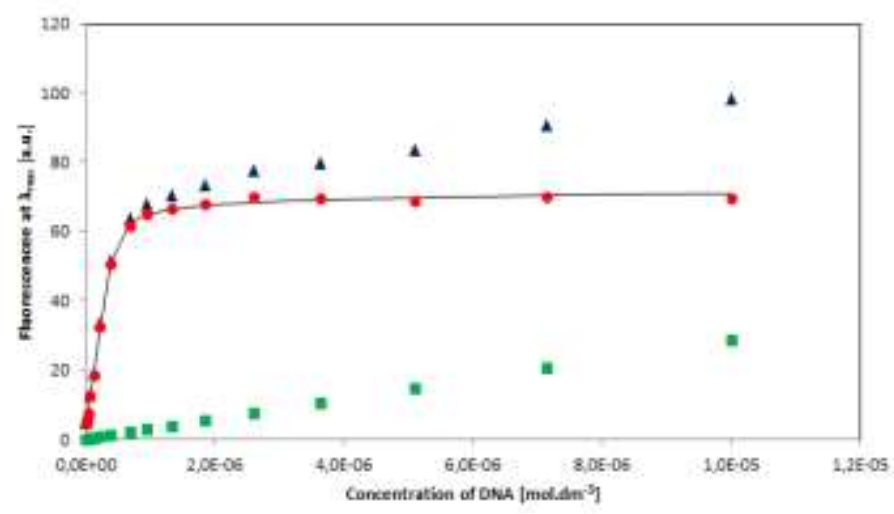


Figure 5. Imino proton region of the $1 \mathrm{D}$ NMR titration spectra of c-kit21T12T21 with chelerythrine. Experimental conditions were: $25^{\circ} \mathrm{C}, \mathrm{H}_{2} \mathrm{O} / \mathrm{D}_{2} \mathrm{O}(9: 1), 25 \mathrm{mM} \mathrm{KH}_{2} \mathrm{PO}_{4}, 70 \mathrm{mM} \mathrm{KCl}, \mathrm{pH}$ 6.9, at different $\mathrm{R}=[$ ligand]/[DNA] ratios.
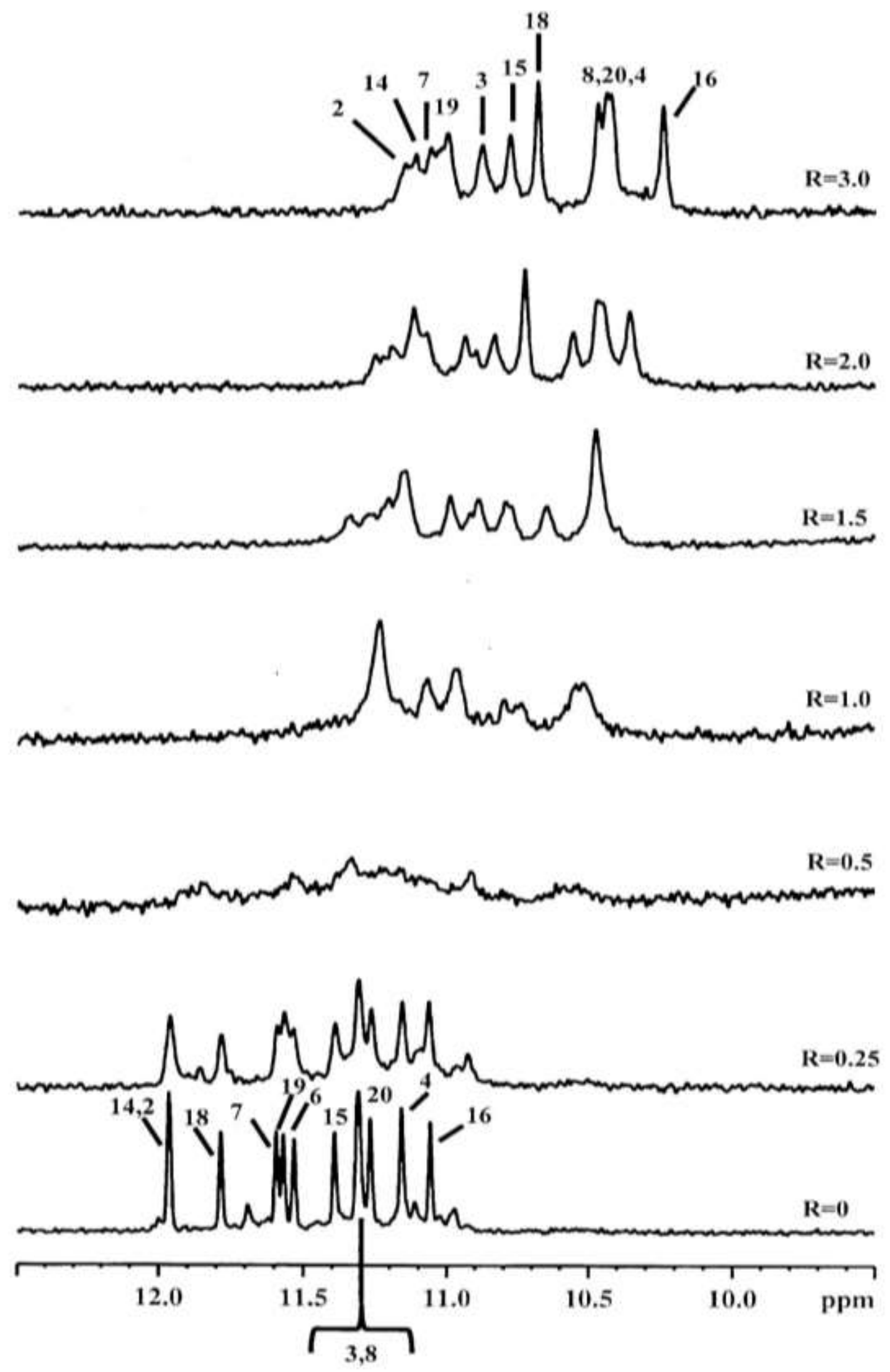
Figure 6. Imino proton region of the $1 \mathrm{D}$ NMR titration spectra of Pu22-T14T23 with (a) sanguilutine and (b) chelerythrine. Experimental conditions were: $25^{\circ} \mathrm{C}, \mathrm{H}_{2} \mathrm{O} / \mathrm{D}_{2} \mathrm{O}(9: 1), 25 \mathrm{mM} \mathrm{KH}_{2} \mathrm{PO}_{4}, 70 \mathrm{mM} \mathrm{KCl}$, pH 6.9, at different $\mathrm{R}$ $=[$ ligand $] /[D N A]$ ratios.
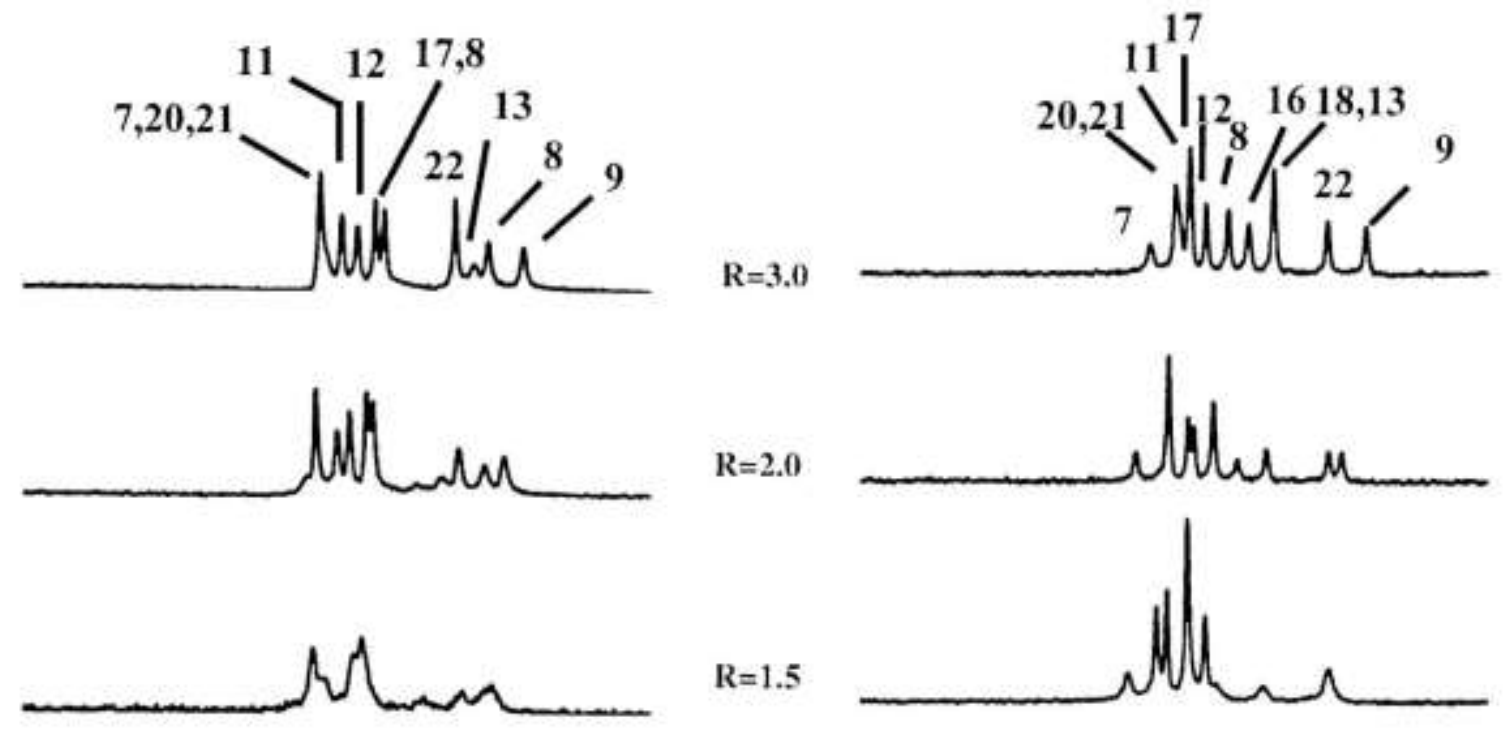

$\mathrm{R}=1.5$

$R=1.0$
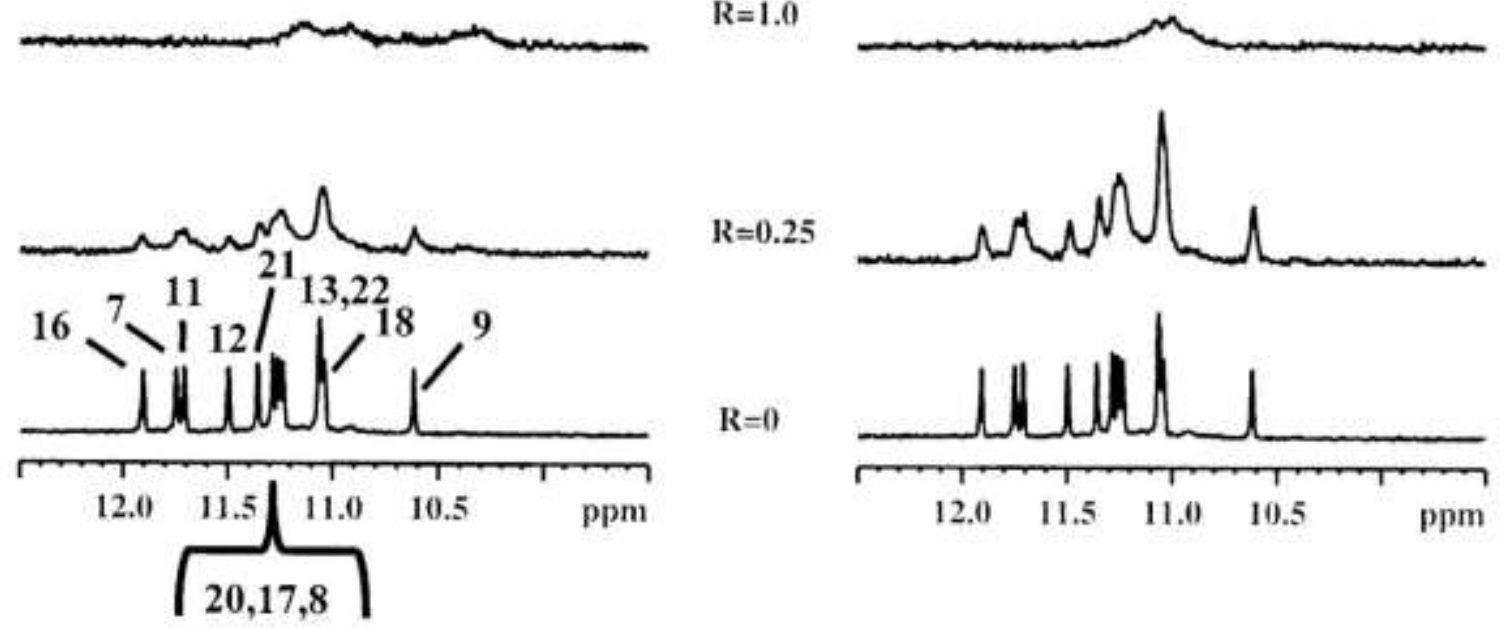
Figure 7. Expanded region of the 2D NOESY spectrum of Pu22-T14T23 / cheleryhthrine complex showing in the boxes: (a) the sequential NOE interactions between the H1 imino protons; (b) and (c) some NOE interactions between the aromatic proton $\mathrm{H} 6$ and $\mathrm{NCH}_{3}$ of chelerythrine and the nucleotide. Experimental conditions are detailed in the main text.

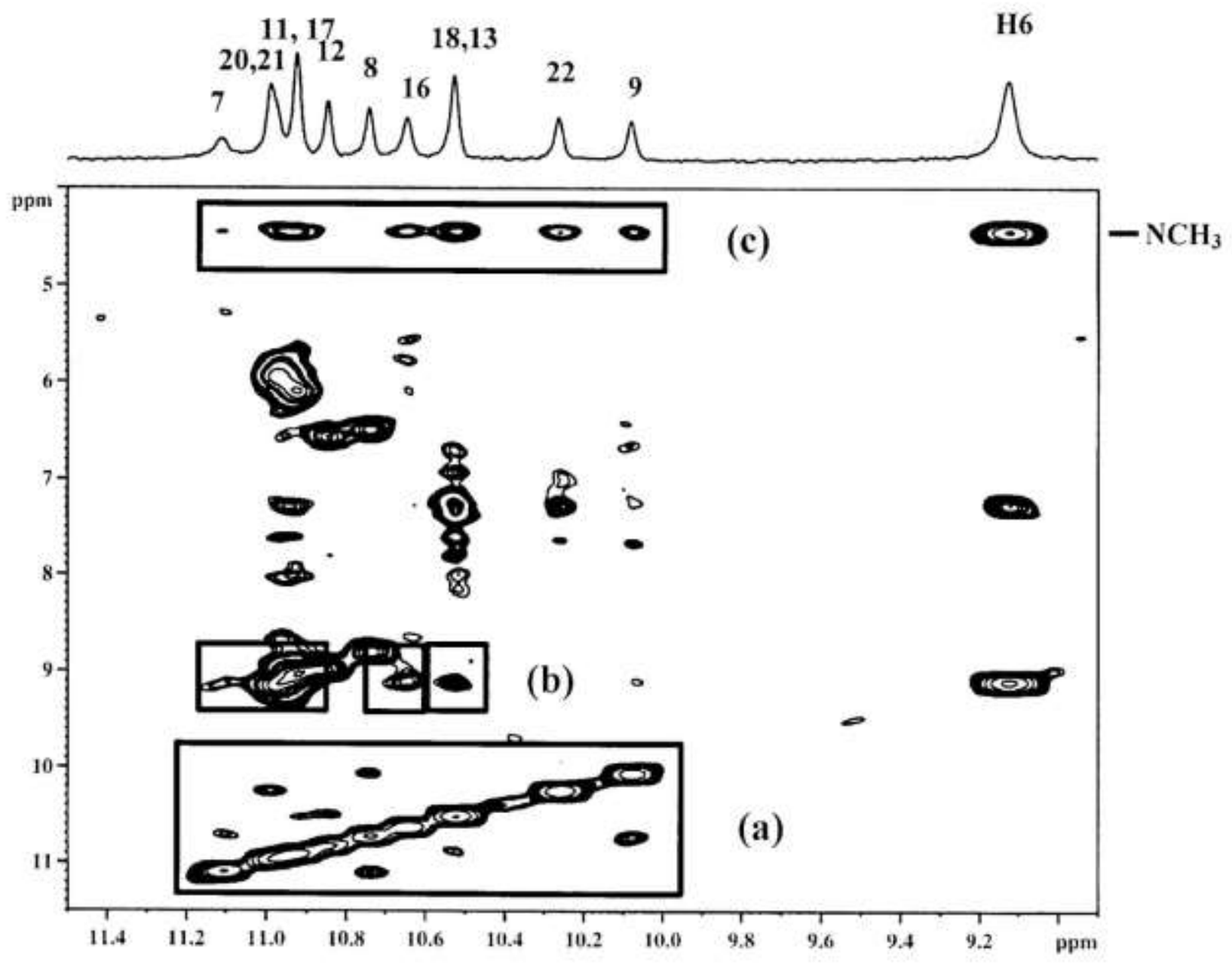




\section{Bibliography}

[1] S. Rybakova, M. Rajecky, J. Urbanova, K. Pencikova, E. Taborska, R. Gargallo, P. Taborsky Chemical Papers. 2013, 67, 568-572.

[2] J. Hammerová, S. Uldrijan, E. Táborská, I. Slaninová Journal of Dermatological Science. 2011, 62, 22-35.

[3] N. Hatae, E. Fujita, S. Shigenobu, S. Shimoyama, Y. Ishihara, Y. Kurata, T. Choshi, T. Nishiyama, C. Okada, S. Hibino Bioorganic \& Medicinal Chemistry Letters. 2015, 25, 2749-2752.

[4] S. J. Chmura, M. E. Dolan, A. Cha, H. J. Mauceri, D. W. Kufe, R. R. Weichselbaum Clinical Cancer Research. 2000, 6, 737-742.

[5] A. Das, A. Mukherjee, J. Chakrabarti Mutation Research-Genetic Toxicology and Environmental Mutagenesis. 2004, 563, 81-87.

[6] T. Ishikawa, T. Saito, H. Ishii Tetrahedron. 1995, 51, 8447-8458.

[7] H. Sato, R. Yamada, M. Yanagihara, H. Okuzawa, H. Iwata, A. Kurosawa, S. Ichinomiya, R. Suzuki, H. Okabe, T. Yano, T. Kumamoto, N. Suzuki, T. Ishikawa, K. Ueno Journal of Pharmacological Sciences. 2012, 118, 467-478.

[8] I. Slaninova, Z. Slunska, J. Sinkora, M. Vlkova, E. Taborska Pharmaceutical Biology. 2007, 45, 131-139.

[9] S. Simeon, J. L. Rios, A. Villar Pharmazie. 1989, 44, 593-597.

[10] K. Bhadra, G. S. Kumar Medicinal Research Reviews. 2011, 31, 821-862.

[11] M. Rajecky, I. Slaninova, P. Mokrisova, J. Urbanova, M. Palkovsky, E. Taborska, P. Taborsky Talanta. 2013, 105, 317-319.

[12] M. Islam, R. Sinha, G. S. Kumar Biophysical Chemistry. 2007, 125, 508-520.

[13] R. Rodriguez, K. M. Miller Nature Reviews Genetics. 2014, 15, 783-796.

[14] P. Murat, S. Balasubramanian Current Opinion in Genetics \& Development. 2014, 25, 22-29.

[15] M. Duchler Journal of Drug Targeting. 2012, 20, 389-400.

[16] A. Siddiqui-Jain, C. L. Grand, D. J. Bearss, L. H. Hurley Proceedings of the National Academy of Sciences of the United States of America. 2002, 99, 11593-11598.

[17] K. W. Lim, S. Amrane, S. Bouaziz, W. X. Xu, Y. G. Mu, D. J. Patel, K. N. Luu, A. T. Phan Journal of the American Chemical Society. 2009, 131, 4301-4309.

[18] V. Singh, M. Azarkh, T. E. Exner, J. S. Hartig, M. Drescher Angewandte Chemie-International Edition. 2009, 48, 9728-9730.

[19] Y. Wang, D. J. Patel Journal of Molecular Biology. 1993, 234, 1171-1183.

[20] G. N. Parkinson, M. P. H. Lee, S. Neidle Nature. 2002, 417, 876-880.

[21] K. N. Luu, A. T. Phan, V. Kuryavyi, L. Lacroix, D. J. Patel Journal of the American Chemical Society. 2006, 128, 9963-9970.

[22] K. W. Lim, V. C. M. Ng, N. Martin-Pintado, B. Heddi, A. T. Phan Nucleic Acids Research. 2013, 41, 10556-10562.

[23] H. Fernando, A. P. Reszka, J. Huppert, S. Ladame, S. Rankin, A. R. Venkitaraman, S. Neidle, S. Balasubramanian Biochemistry. 2006, 45, 7854-7860.

[24] S. T. D. Hsu, P. Varnai, A. Bugaut, A. P. Reszka, S. Neidle, S. Balasubramanian Journal of the American Chemical Society. 2009, 131, 13399-13409.

[25] V. Kuryavyi, A. T. Phan, D. J. Patel Nucleic Acids Research. 2010, 38, 6757-6773.

[26] S. Benabou, R. Eritja, R. Gargallo ISRN Biochemistry. 2013, 2013, 631875.

[27] S. Benito, A. Ferrer, S. Benabou, A. Aviñó, R. Eritja, R. Gargallo Spectrochimica Acta Part A: Molecular and Biomolecular Spectroscopy. 2018, 196, 185-195.

[28] L. Scaglioni, R. Mondelli, R. Artali, F. R. Sirtori, S. Mazzini Biochimica Et Biophysica Acta-General Subjects. 2016, $1860,1129-1138$.

[29] J. X. Dai, M. Carver, L. H. Hurley, D. Z. Yang Journal of the American Chemical Society. 2011, 133, 17673-17680.

[30] J. D. Puglisi, I. Tinoco Methods in Enzymology. 1989, 180, 304-325.

[31] M. Kývala in Solution Equilibria Analysis with the OPIUM Computer Program, Vol. (Ed.^Eds.: Editor), City, 1999, pp.https://web.natur.cuni.cz/ kyvala/opium.html\#4.

[32] A. Ambrus, D. Chen, J. X. Dai, R. A. Jones, D. Z. Yang Biochemistry. 2005, 44, 2048-2058.

[33] X. H. Ji, H. X. Sun, H. X. Zhou, J. F. Xiang, Y. L. Tang, C. Q. Zhao Nucleic Acid Therapeutics. 2012, 22, 127-136.

[34] E. W. White, F. Tanious, M. A. Ismail, A. P. Reszka, S. Neidle, D. W. Boykin, W. D. Wilson Biophysical Chemistry. 2007, 126, 140-153.

[35] A. Guédin, L. Lacroix, J.-L. Mergny, Thermal Melting Studies of Ligand DNA Interactions, 2010.

[36] A. R. O. Cousins, D. Ritson, P. Sharma, M. F. G. Stevens, J. E. Moses, M. S. Searle Chemical Communications. 2014, 50, 15202-15205.

[37] T. Yamashita, T. Uno, Y. Ishikawa Bioorganic \& Medicinal Chemistry. 2005, 13, 2423-2430. 
[38] T. Kimura, K. Kawai, M. Fujitsuka, T. Majima Chemical Communications. 2006, 401-402.

[39] J. Dai, T. S. Dexheimer, D. Chen, M. Carver, A. Ambrus, R. A. Jones, D. Yang Journal of the American Chemical Society. 2006, 128, 1096-1098.

[40] M. Rajecky, K. Sebrlova, F. Mravec, P. Taborsky Plos One. 2015, 10, 16.

[41] P. Ragazzon, J. B. Chaires Methods. 2007, 43, 313-323.

[42] S. Yang, J. F. Xiang, Q. F. Yang, Q. A. Li, Q. J. Zhou, X. F. Zhang, Y. L. Tang, G. Z. Xu Chinese Journal of Chemistry. 2010, 28, 771-780.

[43] I. Slaninova, J. Slanina, E. Taborska Chemicke Listy. 2008, 102, 427-433.

[44] J. Urbanova, P. Lubal, I. Slaninova, E. Taborska, P. Taborsky Analytical and Bioanalytical Chemistry. 2009, 394, 997-1002.

[45] S. Paramasivan, I. Rujan, P. H. Bolton Methods. 2007, 43, 324-331.

[46] T. R. Wilks, A. Pitto-Barry, N. Kirby, E. Stulz, R. K. O'Reilly Chemical Communications. 2014, 50, 1338-1340.

[47] K. Bhadra, G. S. Kumar Biochimica Et Biophysica Acta-General Subjects. 2011, 1810, 485-496.

[48] K. Wu, S. Y. Liu, Q. Luo, W. B. Hu, X. C. Li, F. Y. Wang, R. H. Zheng, J. Cui, P. J. Sadler, J. F. Xiang, Q. Shi, S. X. Xiong Inorganic Chemistry. 2013, 52, 11332-11342.

[49] A. Arora, S. Maiti Journal of Physical Chemistry B. 2008, 112, 8151-8159.

[50] R. Hao, Y. M. Liu, R. G. Zhong Analytical Methods. 2014, 6, 1059-1066.

[51] F. Doria, A. Oppi, F. Manoli, S. Botti, N. Kandoth, V. Grande, I. Manet, M. Freccero Chemical Communications. 2015, 51, 9105-9108.

[52] L. Musso, S. Mazzini, A. Rossini, L. Castagnoli, L. Scaglioni, R. Artali, M. Di Nicola, F. Zunino, S. Dallavalle Biochimica Et Biophysica Acta-General Subjects. 2018, 1862, 615-629. 